\title{
DICIONÁRIOS DE ESPANHOL: UM RECURSO DIDÁTICO AINDA NÃO SUFICIENTEMENTE EXPLORADO
}

\author{
Laura CAMPOS DE BORBA ${ }^{1}$ \\ Mestrado em Lexicografia, Terminologia e Tradução: relações textuais - Universidade \\ Federal do Rio Grande do Sul \\ Félix Valentín BUGUEÑO MIRANDA ${ }^{2}$ \\ Universidade Federal do Rio Grande do Sul
}

RESUMO: O objetivo deste trabalho é propor orientações sobre como o estudante de Letrasespanhol pode empregar dicionários de espanhol como ferramenta auxiliar para aprimorar seu desempenho na língua. No Ensino Superior, ainda que não exista um referencial curricular padrão, a procedência marcadamente espanhola da maioria dos materiais didáticos permite afirmar que a orientação no processo de ensino-aprendizagem de espanhol advém do Plan Curricular del Instituto Cervantes (PCIC, 2006). Em uma passagem específica do PCIC (2006), se menciona o potencial de auxílio do dicionário em determinadas tarefas. Entretanto, não há orientações sobre como empregá-lo. Neste trabalho, propõe-se o uso complementar de certas classes de dicionários monolíngues de espanhol que podem auxiliar o consulente brasileiro a desempenhar-se melhor nas diferentes situações de interação. A metodologia empregada constitui-se de três etapas. Na primeira, elencaram-se os recursos linguísticos atinentes ao ensino de espanhol para estudantes que não possuem o espanhol como língua materna. Na segunda, correlacionaram-se estes recursos com as informações linguísticas de dicionários monolíngues de espanhol. Na terceira etapa, avaliou-se a qualidade da informação oferecida pelas obras, em cada componente canônico que as constitui. Para tanto, consideraram-se os seguintes critérios: a) reflexo da língua em uso; b) habilidades contempladas; c) utilidade para um desempenho adequado em situações de interação. Algumas obras analisadas satisfazem os critérios de avaliação empregados. Para aprimorar seu desempenho na língua com o auxílio dos dicionários, o consulente brasileiro precisa, por um lado, saber atrelar as habilidades requeridas nas distintas situações de interação às obras disponíveis. Por outro lado, é necessário ensinar esse consulente a interpretar informações que, em certos casos, estão presentes de maneira confusa nos dicionários.

PALAVRAS-CHAVE: interação; aprendizagem de espanhol; dicionários de espanhol

ABSTRACT: This paper aims at proposing guidance about how undergraduate students of Spanish language and literature could use Spanish dictionaries as an auxiliary tool to improve their performance in Spanish. In High School, although a standard syllabus does not exist, the Spanish origin of the majority teaching materials allow us to say that guidance in Spanish teaching-learning comes from Plan Curricular del Instituto Cervantes (PCIC, 2006). In a specific passage, PCIC (2006) mentions the dictionaries' help potential in some tasks. However, there is no guidance about how to use a dictionary. We propose a complementary use of certain classes of monolingual Spanish dictionaries which could help Brazilian undergraduate Spanish students. The methodology has three steps. First, we selected some grammatical contents related to teaching Spanish as a foreign language according PCIC (2006). Second, we correlated these grammatical contents with linguistic information in monolingual Spanish dictionaries. In the third step, we assessed the quality of the information offered by these dictionaries. The assessment criteria were: a) if the dictionary reflect the

\footnotetext{
${ }^{1}$ Bolsista de Mestrado do CNPq. Membro do Grupo de Estudos e Pesquisas em Metalexicografia e Lexicografia (grupo certificado pelo $\mathrm{CNPq}$ ).

${ }^{2}$ Líder do Grupo de Estudos e Pesquisas em Metalexicografia e Lexicografia (grupo certificado pelo CNPq).
} 
language usage; $b$ ) what skills are considered; and c) if dictionary information is useful for an adequate performance in situations of interaction. Some dictionaries satisfied the assessment criteria employed. To improve their performance in Spanish, on the one hand, Brazilian students need to know how to relate the language skills with the available information contained in monolingual Spanish dictionaries. On the other hand, it is necessary to teach these students about information interpretation, because, in certain cases, dictionaries do not offer clear explanation.

KEYWORDS: interaction; Spanish learning; Spanish dictionaries

\section{Introdução}

Embora o espanhol seja a segunda língua mais falada do mundo detrás do chinês em suas diferentes variedades e superando até o inglês (cf. Ethnologue. Language of the World), a quantidade de materiais didáticos primários (manuais para o ensino da língua, gramáticas, dicionários, etc.) para o seu ensino como língua estrangeira ${ }^{3}$ oferece ainda resultados que podem ser considerados como discretos, se comparados, por exemplo, com a tradição de ensino de inglês como língua estrangeira ${ }^{4}$. A esses materiais primários é necessário acrescentar um segundo tipo de materiais, que serão chamados de secundários, e que correspondem às guias de orientação didático-pedagógicas à disposição do professor para o planejamento e execução das atividades de ensino-aprendizagem. Nesse quesito, no Brasil, existe uma constante preocupação por auxiliar o professor com orientações didáticopedagógicas (como, por exemplo, através dos Congresos Brasileños de Profesores de Español, iniciados em $1985^{5}$ ). Embora se perceba que há a tentativa de oferecer contribuições atinentes à língua propriamente dita, isto é, entendê-la e usá-la como uma ferramenta linguística, também é perceptível que o ensino-aprendizagem do espanhol (e das línguas estrangeiras em geral) se entende ainda muito mais da perspectiva de uma intenção comunicativa eficiente e de uma dimensão cultural. A influência da abordagem comunicativa é, assim, um fator claramente dominante no ensino da língua. Nesse contexto, Siepmann e Bürgel (2016, p. 141) não deixam de ter razão quando comentam que a competência comunicativa [kommunikative Kompetenz] degradou [hat herabgestuft] a percepção da língua

\footnotetext{
${ }^{3}$ Para fins desse trabalho mantem-se a designação língua estrangeira, embora no Brasil se empregue, às vezes, língua adicional. Há pesquisadores na área da Linguística Aplicada, tais como Judd et al. (2001) e Schlatter e Garcez (2009), que propõem o uso do termo língua adicional em detrimento de língua estrangeira. Dentre os argumentos defendidos estão as possíveis associações ao termo língua estrangeira, como uma língua "estranha, exótica ou, talvez, alheia" [strange, exotic or, perhaps, alien] (JUDD et al., 2001, p. 6), ou ainda possíveis julgamentos da língua estrangeira como superior ou inferior à língua materna. Schlatter e Garcez (2009, p. 128), por sua vez, defendem que cada nova língua aprendida é adicionada àquela(s) que já sabe. Nesta dissertação, entretanto, será mantido o termo língua estrangeira por duas razões. Primeiramente, o termo que consta nos documentos do Ministério da Educação brasileiro referentes às normas reguladoras do Ensino Básico e do Ensino Superior é língua estrangeira. Os PCN (1998, 2000, 2002), a nova BNCC (2016) e as Diretrizes Curriculares Nacionais do curso de Letras (CNE/CES 492/2001) são alguns exemplos de documentos nos quais usa-se língua estrangeira. Em segundo lugar, as publicações internacionais referentes ao ensino de língua espanhola (a qual será considerada para fins desta dissertação) entre falantes cuja língua materna não é o espanhol é Español como Lengua Extranjera (na tradução ao português, Espanhol como Língua Estrangeira). Em suma, nossa decisão tem por intuito usar uma terminologia que esteja em conformidade tanto com os documentos oficiais que regulam o ensino de línguas no Brasil como com as publicações que circulam nos veículos de divulgação da produção científica.

${ }^{4}$ Cita-se, a modo de exemplificação, a longa lista de materiais de editoras como Oxford, Cambridge, Longman, etc., assim como linhas de pesquisa já solidamente instauradas, tais como Teaching English as a Second Language (TESL) ou Teaching English as a Second ou Foreign Language (TESOL).

${ }^{5}$ Para uma história dessa iniciativa e desses Congressos, cf. Actas del XII Congreso Brasileño de Profesores de Español (2010, p. 14).
} 
estrangeira como sistema complexo que um indivíduo aprendiz deve dominar para seu desempenho eficiente em situações de interação.

Sem deixar de considerar as contribuições da perspectiva comunicativa no ensinoaprendizagem de línguas, o foco deste trabalho recai sobre um aspecto que, conforme comentado no parágrafo anterior, ainda deixa a desejar no ensino comunicativo: a formação em língua espanhola enquanto ferramenta linguística. Entendemos que tal formação é fundamental, a começar pelo ensino da língua em cursos de Letras-espanhol. Nesses cursos, os estudantes precisam aprender recursos linguísticos, necessários tanto para um desempenho adequado em situações de interação por meio do espanhol como para o exercício atividades profissionais que requeiram aplicação de conhecimentos do idioma (como docência e tradução, por exemplo).

Nos cursos de Letras-espanhol, o ensino-aprendizagem de tais recursos pode ser complementado pelo emprego de materiais didáticos, como os dicionários monolíngues de espanhol; no entanto, ainda se sabe muito pouco a respeito do potencial de auxílio desse tipo de material. Em vista desse cenário, nosso objetivo é propor orientações sobre como o estudante de Letras-espanhol pode empregar dicionários de espanhol como ferramenta auxiliar para aprimorar seu desempenho na língua.

\section{Documentos norteadores do ensino-aprendizagem de espanhol}

Não há, no Brasil, um documento norteador para o ensino-aprendizagem de espanhol no âmbito universitário. A única orientação fornecida pelo Ministério da Educação em relação aos cursos de Letras consiste nas Diretrizes Curriculares Nacionais do curso de Letras (CNE/CES, 492/2001). Trata-se de um documento que regula a organização de cursos de Letras em instituições de Ensino Superior, sem, no entanto, dispor de informações sobre o currículo de ensino de línguas estrangeiras nesses cursos.

Perante essa situação, há duas opções possíveis. Por um lado, poder-se-ia afirmar que simplesmente não há orientação alguma; ou, por outro lado, se poderia tratar de estabelecer se há algum fio condutor a partir dos materiais didáticos empregados no ensino da língua. Nesse âmbito, é possível constatar que a maioria dos materiais didáticos de ELE usados na atualidade é oriunda da iniciativa editorial espanhola ${ }^{6}$.

Em função dessa constatação, é possível afirmar também que esses materiais foram desenhados à luz de parâmetros advindos do Plan Curricular del Instituto Cervantes (PCIC, 2006). Portanto, se pode concluir que, na grande maioria dos casos, o ensino-aprendizagem de espanhol no país está norteado pelo PCIC (2006).

O PCIC (2006) constitui um completo programa para o ensino de espanhol desde o nível iniciante até o superior, conforme se pode apreciar no quadro a seguir.

\footnotetext{
${ }^{6}$ Na rubrica "Libros de Texto - Diversos" de Eres Fernández (2012), elenca-se um total de 210 manuais para o ensino do espanhol, dos quais 77,6\% correspondem a materiais de origem editorial espanhola.
} 
Quadro 1 - escala de níveis de referência do PCIC (2006)

\begin{tabular}{|l|l|l|}
\hline \multicolumn{1}{|c|}{$\begin{array}{c}\text { Usuário Básico } \\
\text { (iniciante) }\end{array}$} & \multicolumn{1}{|c|}{$\begin{array}{c}\text { Usuário Independente } \\
\text { (avançado) }\end{array}$} & \multicolumn{1}{c|}{$\begin{array}{c}\text { Usuário Competente } \\
\text { (superior) }\end{array}$} \\
A1 = acesso & B1 = umbral & $\begin{array}{l}\text { C1 = domínio operativo eficaz } \\
\text { C2 = Maestria }\end{array}$ \\
\hline
\end{tabular}

Fonte: PCIC (2006)

Além dessa divisão clara dos níveis de proficiência, que se fundamenta nos objetivos que o aprendiz deve atingir para ser considerado um usuário $\mathrm{A} 2$ ou $\mathrm{C} 1$, por exemplo, o PCIC (2006) fornece uma descrição dos recursos linguísticos (funções) atinentes a cada nível de proficiência. Eis um exemplo:

Figura 1 - exemplo de recursos linguísticos de níveis A1 e A2

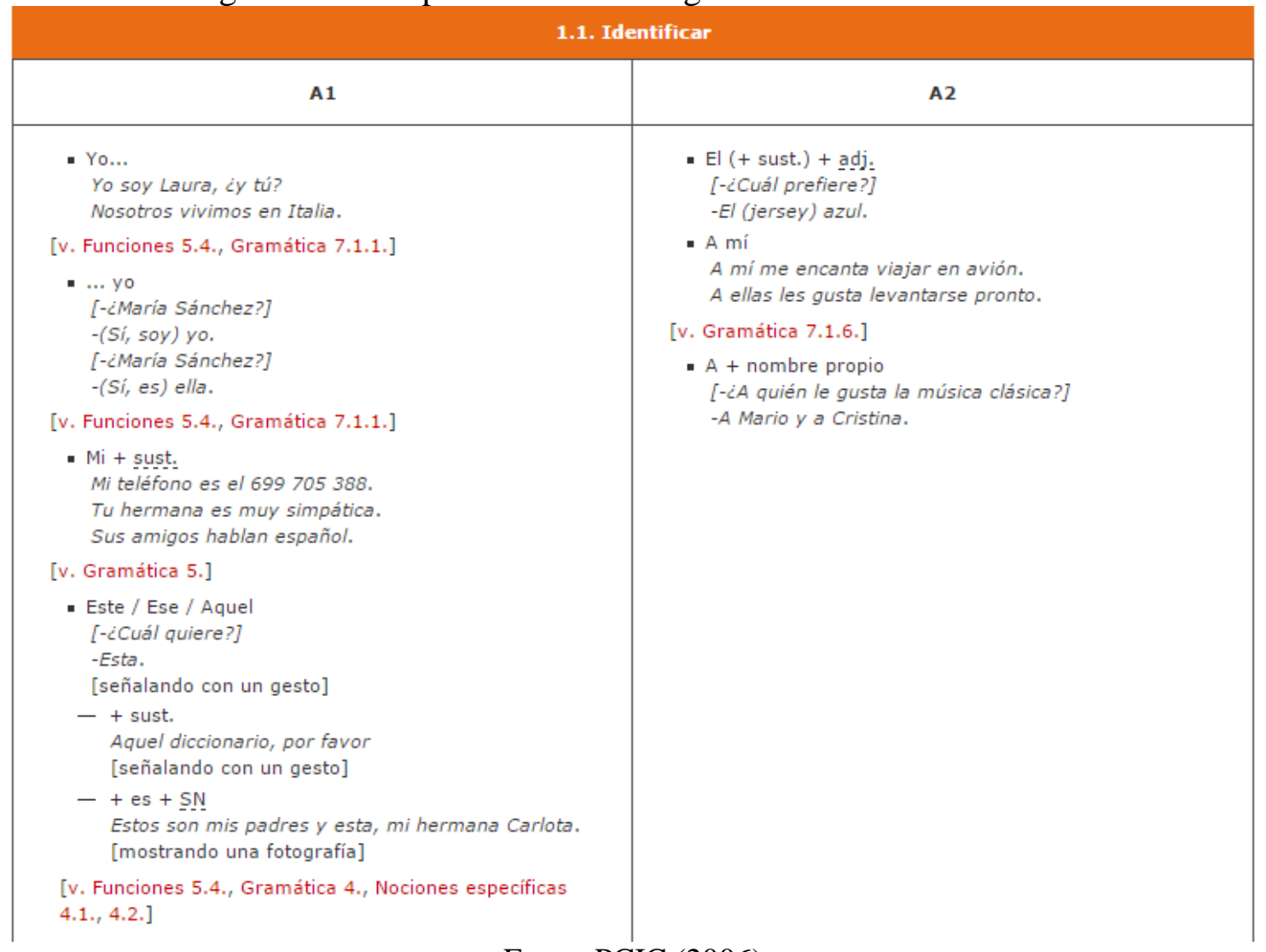

Fonte: PCIC (2006)

\section{O PCIC (2006) e o uso do dicionário}

O PCIC (2006a) oferece algumas orientações referentes ao uso do dicionário, compreendidas dentro de um capítulo intitulado "Procedimentos de aprendizagem", mais precisamente em rubricas que se referem a procedimentos e estratégias de aprendizagem. Assim, por exemplo, no parágrafo dedicado à gestão de recursos, meios e oportunidades de aprendizagem e de uso da língua [Gestión de recursos, medios y oportunidades de aprendizaje y uso de la lengua], mais especificamente no que diz respeito à exploração de fontes de informação e de consulta, sugere-se que o aprendiz utilize o dicionário (p. 484-485). Em outros dois tipos de estratégia de aprendizagem, chamados de ensaio e repetição [ensayo y 
repetición] (p. 493-494) e compensação [compensación] (p. 495), recomenda-se o uso de dicionário para a busca do significado e de sinônimos. Uma leitura mais atenta permite inferir que a consulta do dicionário, no primeiro caso (busca de significado), corresponde à perspectiva semasiológica, enquanto que, no segundo caso (busca de sinônimos), corresponde à perspectiva onomasiológica ${ }^{7}$.

Essas sugestões, no entanto, são poucas e não completamente claras na sua condição de instrução em relação ao emprego de dicionários. Em relação aos níveis iniciais (A1 e A2), há um certo consenso em relação ao potencial de auxílio de dicionários bilíngues portuguêsespanhol e espanhol-português. Por outro lado, no que concerne aos níveis avançados (B1 e B2) e superiores ( $\mathrm{C} 1$ e $\mathrm{C} 2)$, faltam orientações acerca de quais dicionários seriam mais adequados. Uma primeira opção a ser considerada são os dicionários para aprendizes (learner's dictionaries). Trata-se de obras compiladas, em princípio, com o objetivo de auxiliar os estudantes de língua estrangeira que já passaram dos níveis iniciais de aprendizagem (e para os quais os dicionários bilíngues já não são suficientes). No entanto, e conforme se discutirá na seção a seguir, os dicionários para aprendizes de língua espanhola disponíveis apresentam um potencial de auxílio aquém do desejado.

\section{Os dicionários de aprendizes na tradição lexicográfica de língua espanhola}

Ao seio da tradição de ensino aprendizagem de língua inglesa, desenhou-se uma classe específica de dicionários voltados ex professo para o ensino-aprendizagem de língua inglesa como língua estrangeira: os learner's dictionaries ${ }^{8}$. Esse fato deu origem a uma linha de desenho e pesquisa chamada de lexicografia pedagógica (cf. HARTMANN e JAMES, 2001, s. v. pedagogical lexicography). $\mathrm{O}$ avanço das pesquisas na área se reverteu em obras lexicográficas tais como Oxford Advanced Learner's Dictionary (OALD, 2010), Collins Cobuid Advanced Dictionary (CCAD, 2010), Longman Dictionary of Contemporary English (LDCE, 2014) e Macmillan English Dictionary for Advanced Learners (MDAL, 2007) para o inglês; Le Robert \& CLE International Dictionnaire du français (RobCLE, 1999) para o francês; Langenscheidt Großwörterbuch Deutsch als Fremdsprache (LGwtbDaF, 2015) para o alemão; dentre outras. Para o espanhol, no entanto, a situação é muito diferente. Primeiramente, os dicionários que poderiam ser classificados como dicionários de aprendizes são poucos: Señas - Diccionario para la Enseñanza de la Lengua Española para Brasileños (DEB, 2008), Diccionario Salamanca - Español para Extranjeros (DSLEE, 2006) e Diccionario de la Lengua Española para estudiantes de Español (DEE, 2002). Em segundo lugar, nenhum deles atende minimamente às necessidades de um estudante brasileiro de espanhol nem aos requerimentos dos manuais de ensino de língua.

Em Bugueño Miranda (2006), é feita uma análise de DEB (2008), salientando-se, por exemplo, que a definição macroestrutural qualitativa (isto é, que tipo de unidades léxicas compõem a macroestrutura) apresenta uma significativa quantidade de lemas de baixíssima

\footnotetext{
${ }^{7}$ A perspectiva semasiológica diz respeito à apresentação de informações em um dicionário a partir do signolema para a definição; por essa razão, atribui-se à semasiologia a possibilidade de auxílio em tarefas de compreensão de língua. A perspectiva onomasiológica, por outro lado, está relacionada à apresentação de informações a partir de uma definição ou um signo-lema para outro signo-lema. Em função disso, dicionários onomasiológicos são relacionados à função de produção de língua.

${ }^{8}$ Para uma analise de dicionários de aprendizes do inglês e do alemão, cf. Bugueño Miranda; Reolon (2010).
} 
frequência no espanhol ${ }^{9}$. Da mesma forma, aspectos tão básicos como uma descrição apurada dos papeis argumentais aparecem também completamente desatendidos. Os resultados dessa análise continuam a ter validade, já que as novas edições de DEB (2008) são, na verdade, reimpressões. No que diz respeito a DEE (2002), a situação não é diferente. Ao igual que no caso anterior, percebe-se um inchaço macroestrutural ${ }^{10}$ (cf. BUGUEÑO MIRANDA; FARIAS (2008) para esse conceito). No plano microestrutural, por sua vez, há uma melhora em relação a DEB (2008) no que diz respeito aos papeis argumentais. Eis alguns exemplos:

\section{Quadro 2 - microestrutura do DEE (2002)}

\begin{tabular}{|c|c|c|}
\hline $\begin{array}{l}\text { atribuir (...) tr. y prnl. 1. Aplicar, } \\
\text { conceder } \mid \text { alguien } \mid \text { (una cosa) } \\
\text { una persona): Van a atribuirle la } \\
\text { medalla al mérito militar } \mathbf{2} \text {. } \\
\text { Asignar } \mid \text { alguien } \mid \text { (una cosa) (a } \\
\text { una persona) como de su } \\
\text { competencia: Me han atribuido la } \\
\text { responsabilidad de las ventas } \mathbf{3} \text {. } \\
\text { Achacar, imputar | alguien } \mid \text { (una } \\
\text { cosa) (a una persona): Le } \\
\text { atribuyeron un crimen que no } \\
\text { había cometido (...) }\end{array}$ & 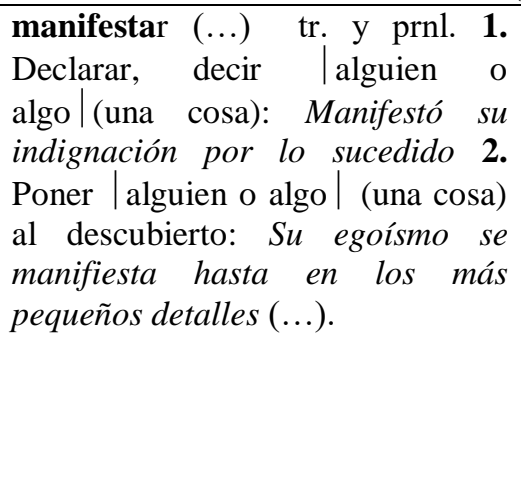 & $\begin{array}{l}\text { entregar 1. Tr. Poner } \mid \text { alguien } \\
\text { (una cosa) en poder de (una } \\
\text { persona): Entregó la llave al } \\
\text { portero. } \\
\text { delgado, da adj. | persona } \mid \text { Que } \\
\text { actúa en nombre de outra (...). } \\
\text { delirante (...) adj. Que sufre } \\
\text { desvaríos }(. . .) \text {. } \\
\text { deportista (...) adj. y com. } \\
\text { |persona Que es aficionado a los } \\
\text { deportes o que practica alguno de } \\
\text { ellos }(. . .) \text {. }\end{array}$ \\
\hline
\end{tabular}

Fonte: DEE (2002, s.v. atribuir, manifestar, entregar, delgado, delirante, desportista)

A marcação dos papeis argumentais distingue entre sujeito, objeto direto (acusativo) e objeto indireto (dativo). No entanto, no Front Matter, se indica simplesmente que os segmentos da paráfrase dispostos entre parêntesis correspondem aos complementos, sem assinalar de que classe de complemento se trata em cada caso (com a exceção da posição de sujeito, que vai assinalada entre barras). Aferir um determinado papel argumental para cada segmento marcado consiste em um ônus para o consulente. Embora os verbetes atribuir e manifestar contam com exemplos que serviriam para salientar as particularidades sintático semânticas de cada verbo, os exemplos nem sempre se demostram elucidativos, como a acepção 2 s.v. atribuir, em que o pronome átono dativo aparece na primeira pessoa do singular - que, como se sabe, é sincrética. Um aspecto mais complexo nesse mesmo âmbito é como o potencial consulente poderia saber que o verbo entregar apresenta uma tendência clara a levar dativo, considerando que a formulação da paráfrase explanatória não permite inserir o segmento "(a una persona)". Além disso, o usuário tampouco conta com o potencial auxílio do exemplo, pois o mesmo foi formulado sem a presença do pronome átono dativo.

O terceiro dicionário de aprendizes de espanhol é DSLEE (2006). Ao igual que nos casos anteriores, chama a atenção uma clara tendência a um inchaço macroestrutural ${ }^{11}$. No âmbito da microestrutura, DSLEE (2007) demonstra um desempenho similar a DEE (2002),

\footnotetext{
${ }^{9}$ Para efeitos de cotejo dos três dicionários, emprega-se o Corpus de Referencia del Español Actual (CREA, 2010).

${ }^{10}$ Para análise, foram escolhidas as letras $\mathrm{C}$ e L, constatando-se que os lemas casquén, castrato, catavivos, cáustico, cazurro, cegato, ceporro, chepa, chirigota, chivarse, chufla, combar, condal, copear, copeo, correveidile, lacón, ladilla, lagarta, lametón,lapo, laxo, lebrel, liante, libar, licantropia, ligón, linimento, lisiar, llamador, loar, longuis, loseta, lúbrico, ludópata y ludopatía são de baixa ocorrência no espanhol.

${ }^{11}$ A análise das letras $\mathrm{B}, \mathrm{F}$ e $\mathrm{O}$ revelou palavras de baixíssima frequência ou simplesmente que não puderam ser documentadas, tais como babeo, babi, estar em Babia, babosada, babucha, baca, bacaladero, bacón, -na, bachicha, bailón, -na, bajamento, balacear, balarrasa, bálago, bangaña, bayetilla, berreta, bolinga, bolsín, borbullear, bóreas, brear, butaque faje, falopearse, fangote, fatuto, fayuca, fesa, feta, flámula, fodongo, -ga, fórmica, fotuto, freza, fumista, funyi, futesa, oblar, oploteca, otimates, orificar, orvallo.
} 
isto é, há uma melhora na apresentação das informações de cunho sintático-semântico, como se pode apreciar nos exemplos do Quadro 3 (v. página a seguir).

Quadro 3 - microestrutura do DSLEE (2006)

\begin{tabular}{|c|c|c|}
\hline $\begin{array}{l}\text { entregar v.tr. } 1 \text { Dar <una persona> [una } \\
\text { cosa] a [otra persona]: Me han entregado } \\
\text { este papel (...). } \| \text { v.tr. / prnl. } 2 \text { Hacer <una } \\
\text { persona> que [otra persona] pase a poder } \\
\text { de [los enemigos o las autoridades]: Los } \\
\text { secuestradores han dicho que entregarán } \\
\text { a los rehenes (...). Se entregó a las } \\
\text { autoridades militares. } 3 \text { Hacer depender } \\
\text { <una persona> el destino o la voluntad de } \\
\text { [una persona] de [otra persona o una } \\
\text { cosa]: Los romanos entregaban a los } \\
\text { cristianos a los leones (...). }\end{array}$ & $\begin{array}{l}\text { eventual adj. } 1 \text { (antepuesto / } \\
\text { pospuesto) Que no es seguro o } \\
\text { fijo, o que puede ocurrir o no, } \\
\text { dependiendo de } \\
\text { circunstancias: las } \\
\text { eventual, empleo eventual, } \\
\text { ingresos eventuales }(. . .) \| a d j . \\
/ \text { s.m. y } f \text {. } 2 \text { (ser / estar) } \\
\text { [Trabajador] que presta } \\
\text { temporariamente sus servicios } \\
\text { en una empresa (...). }\end{array}$ & $\begin{array}{l}\text { gerencia s.f. } 1 \text { (no contable) } \\
\text { Oficio y funciones del gerente } \\
\text { (...) } 2 \text { Conjunto de gerentes de } \\
\text { una empresa }(. . .) \text {. }\end{array}$ \\
\hline
\end{tabular}

Fonte: DSLEE (2006, s.v. entregar, eventual, gerencia)

S.v. entregar, a primeira acepção marca claramente os argumentos requeridos pelo verbo. No entanto, o exemplo demonstra ser pouco discriminativo, pois o átono dativo me está na primeira pessoa, que, morfologicamente, constitui um sincretismo com o átono acusativo. Assim, o consulente não tem como comprovar que o verbo, de facto, exige um objeto dativo. Acertada, no entanto, foi a decisão de se empregar o segmento informativo do exemplo para exemplificar o uso pronominal do verbo, ressaltando-se em negrito o respectivo pronome.

Um último aspecto s.v. entregar (DSLEE, 2007) que merece atenção é o uso de preposição diante dos dois complementos no segmento informativo do exemplo na acepção 3: "Los romanos entregaban a los cristianos a los leones". DPDe (2005, s.v. a) estabelece que, nesse caso, a preposição do objeto direto (a los cristianos) é optativa. Dado que os dois usos são igualmente legítimos, seria muito prudente assinalar esse fato encerrando a preposição entre parênteses ou apresentando uma nota de uso, como acontece, por exemplo, s.v. ergo.

Ainda no âmbito da sintaxe, DSLEE (2006) estabelece para cada adjetivo a sua posição ante- ou posposta ao nome, uma informação que não consta nos outros dois dicionários e que é pertinente, como acontece, por exemplo, s.v. eventual. Na acepção 2 do mesmo verbete, acrescenta-se um segundo tipo de informação sintática, que é o tipo de verbo auxiliar com o qual se pode combinar o adjetivo. Porém, o uso de estar eventual não pode ser documentado no CREA (2010). Tampouco foi possível documentar o uso de eventual como substantivo. Finalmente, o dicionário tampouco faz jus completamente ao estado atual da língua no plano microestrutural ao orientar o usuário que o lexema gerencia não admite plural. A consulta ao CREA (2010) revela que o uso majoritário é em singular, mas há evidências no próprio CREA (2010) que já atestam o uso plural. Nessas circunstâncias, uma nota de uso teria sido muito útil.

Em resumo, embora se percebam melhoras, os dicionários voltados para o aprendiz de ELE continuam a apresentar uma utilidade aquém das necessidades dos seus potenciais consulentes. Tendo em vista o auxílio ainda insuficiente que tais obras poderiam oferecer ao estudante brasileiro de Letras-espanhol, o foco deste trabalho recai sobre o potencial de outra 
classe de dicionários, a qual conta com muitos expoentes na tradição lexicográfica hispânica: os dicionários monolíngues para falantes de espanhol como língua materna.

\section{O potencial dos dicionários monolíngues para falantes de espanhol como língua materna}

Neste trabalho, serão analisados quatro dicionários de espanhol compilados para falantes de espanhol como língua materna: 1) Diccionario de la Real Academia Española (DRAEe, 2014, edição online); 2) Diccionario Panhispánico de Dudas (DPDe, 2005, edição online); 3) Diccionario Clave de Uso del Español Actual (DiClave, 2012, edição online); e 4) Diccionario de Uso del Español (DUE, 2001). O primeiro é um dicionário geral de língua; o segundo, um dicionário de dúvidas; o terceiro e o quarto, por sua vez, são dicionários de uso. Todos possuem a função de auxiliar em tarefas de compreensão de língua (ainda que, em alguns casos, as informações fornecidas nos verbetes possam, perfeitamente, auxiliar também na produção).

Os critérios de escolha das obras dizem respeito à disponibilidade de acesso às mesmas e ao prestígio que possuem entre os falantes de espanhol como língua materna. Por um lado, os três primeiros constituem obras com acesso gratuito pela internet. Por outro lado, o DUE (2001) possui um prestígio consumado entre os falantes de espanhol.

Como metodologia, serão adotadas as seguintes decisões: 1) elencar recursos linguísticos de ELE a partir do PCIC (2006); 2) correlacionar tais recursos com informações presentes no elenco de dicionários descrito ad supra; e 3) avaliar a qualidade da informação fornecida. Serão considerados os seguintes critérios de avaliação: a) reflexo da língua em uso; b) as habilidades contempladas e a função do dicionário; e c) a utilidade da informação fornecida para um desempenho adequado em situações de interação.

$\mathrm{Na}$ etapa 1 da metodologia, elencaram-se os seguintes recursos linguísticos para posterior avaliação dos dicionários, selecionados aleatoriamente:

- Nível B1: apócope de adjetivo masculino anteposto a substantivos masculinos no singular (PCIC, 2006b, p. 54). Exemplo: buen.

- Nível B2: substantivos femininos no singular que começam com o fonema /a/ tônico com artigo e quantificador no masculino singular (PCIC, 2006b, p. 52). Exemplo: agua.

- Nível C1: pronome sujeito neutro de $3^{\text {a }}$ pessoa (PCIC, 2006c, p. 62). Exemplo: ello.

- Nível C2: expressões com ser (PCIC, 2006c, p. 89). Exemplo: ser más papista que el Papa.

Longe de esgotar todos os casos nos quais essas quatro particularidades se manifestam, analisar-se-á o tratamento atribuído pelos quatro dicionários por meio dos exemplos listados acima. Tais exemplos são fornecidos pelo próprio PCIC (2006) com o objetivo de ilustrar brevemente como cada recurso linguístico elencado pode se manifestar na língua. Os resultados da análise (etapas 2 e 3), por sua vez, serão comentados na seção a seguir. 
Análise

Em primeiro lugar, em relação à apócope do adjetivo masculino bueno, cabe assinalar que o DRAEe (2014), o DPDe (2005) e o DiClave (2012) tratam dessa particularidade morfofonológica do espanhol.

O DRAEe (2014, s.v. buen) apresenta suas informações de uma maneira mais simplificada, abreviando a observação "Usado ante sustantivo masculino singular". Por essa razão, a leitura do verbete exige mais atenção por parte do consulente, conforme se pode visualizar na Figura 2 abaixo:

Figura 2 - s.v. buen no DRAEe (2014)

buen Apóc. 1. adj. buen U. ante s. m. sing. Buen año. Buen despertar

Fonte: DRAEe (2014, s.v. buen)

O DiClave (2012), por sua vez, apresenta a particularidade morfológica de buen através de uma nota de uso de fácil compreensão ao final do verbete:

Figura 3 - s.v. buen no DiClave (2012)

buen buen adj. $\rightarrow$ bueno MORFOLOGIA Apócope de bueno ante substantivo masculino singular.

Fonte: DiClave (2014, s.v. buen)

Finalmente, o DPDe (2005) fornece uma explicação bastante detalhada e com exemplos (cf. Figura 4 na próxima página). A exposição mais extensa e aprofundada do comportamento de buen permite-nos afirmar que nem todo e qualquer estudante de níveis mais avançados de ELE poderia aproveitar as informações fornecidas. Na verdade, o usuário provavelmente mais capaz de se beneficiar da consulta ao DPDe (2005) é o estudante de Letras-espanhol.

Figura 4 - s.v. buen no DPDe (2005)

buen $\rightarrow$ bueno, 1.

bueno -na. 1. [...] Se apocopa siempre en la forma buen cuando precede a un sustantivo masculino singular, aunque entre ambos se interponga otra palabra: mi buen amigo, un buen primer libro. No se apocopa, sin embargo, cuando lo que se interpone entre el adjetivo y el sustantivo es la preposición de: el bueno de Pedro. La apócope es opcional si bueno aparece antepuesto y coordinado con otro adjetivo: "Con qué gusto encontraba a mi bueno y viejo compañero del primer arreo" (Güiraldes Segundo [Arg. 1926]) [...]

Fonte: DPDe (2005, s.v. buen)

Em segundo lugar, e no tocante aos substantivos femininos com fonema /a/ tônico inicial (agua), somente o DiClave (2012) e o DPDe (2005) assinalam esse fato linguístico do 
espanhol. Ambos oferecem uma explanação completa e relativamente simples, por meio de uma nota de uso, no caso do DiClave (2012), e no próprio verbete, no caso do DPDe (2005). As figuras 5 e 6 , a seguir, reproduzem os verbetes das duas obras:

Figura 5 - s.v. agua no DiClave (2012)

agua [...] MORFOLOGIA Por ser un sustantivo femenino que empieza por a tónica o acentuada, va precedido de el, un, algún, ningún y de las formas femeninas del resto de los determinantes.

Fonte: DiClave (2012, s.v. agua)

Figura 6 - s.v. agua no DPDe (2005)

agua. 1. 'Sustancia líquida inodora, incolora e insípida en estado puro'. Este sustantivo es femenino. Al comenzar por /a/ tónica, exige el uso de la forma el del artículo definido si entre ambos elementos no se interpone otra palabra $(\rightarrow \underline{\mathrm{el}}, 2.1)$, pero los adjetivos deben ir en forma femenina: «Podía verse a lo lejos el agua clara» (Regás Azul [Esp. 1994]). [...]

Fonte: DPDe (2005, s.v. agua)

Em terceiro lugar, e no que concerne ao pronome sujeito neutro ello, os quatro dicionários o lematizam.

O DRAEe (2014) apresenta apenas a classificação morfológica de ello como pronome neutro (cf. Figura 7 na próxima página). No entanto, carece-se de informações a respeito da função desse pronome. Ao final do verbete, há também um fator que pode confundir o consulente brasileiro: a inclusão de ello enquanto substantivo masculino. Não foram encontrados registros de uso de ello enquanto unidade léxica da área da psicologia em nenhum dos dois principais corpora do espanhol contemporâneo - o CREA (2010) e o Corpus del Español del Siglo XXI (CORPES, 2016) ${ }^{12}$. O dicionário deixa, então, de cumprir com o primeiro critério de avaliação (qual seja, o reflexo da língua em uso).

Figura 7 - s.v. ello e él no DRAEe (2014)

ello $\underline{\mathrm{V}}$ él.

él, ella Neutro ello. [...] ello 1. m. Psicol. En el psicoanálisis de Freud, fuente inconsciente de toda energía psíquica, que contiene la totalidad de los instintos reprimidos y se rige solo por el principio del placer.

Fonte: DRAEe (2014, s.v. ello, él)

O DiClave (2012) e o DPDe (2005), por sua vez, incluem a classificação morfológica e evidenciam a função do pronome, conforme reproduzem as figuras 8 e 9 a seguir:

${ }^{12}$ O CREA (2010) considera o intervalo entre 1975 e 2004. Já o CORPES (2016) considera o intervalo entre 2001 e 2012). 
Figura 8 - s.v. ello no DiClave (2012)

ello e-llo pron. pers. Forma de la tercera persona del singular que corresponde a la función de sujeto, de predicado nominal o de complemento precedido de preposición: Si él no quiere visitarte, ello no impide que lo visites tú a él. ¡Vamos, a ello, que tú puedes! [...]

Fonte: DiClave (2012, s.v. ello)

Figura 9 - s.v. ello no DPDe (2005)

ello. 1. Forma neutra del pronombre personal tónico de tercera persona del singular. [...] En la lengua actual puede tener como antecedente oraciones, pronombres o grupos nominales neutros y varios sustantivos de cosa considerados conjuntamente: Me enfrenté con mi jefe y pagué por ELLO; [...]

Fonte: DPDe (2005, s.v. ello)

Já o DUE (2001), assim como os dois dicionários anteriores, especifica tanto a classe gramatical como a função do pronome. Além das informações fornecidas no verbete, há uma remissão ao "Apéndice II", no back matter. Em um dicionário, o back matter é um componente não canônico localizado após a nominata do dicionário e no qual, normalmente, são incluídos quadros de conjugação verbal, entre outras informações. No "Apéndice II" do DUE (2001), há, novamente, uma explicação a respeito da função de ello. Curiosamente, tal informação é apresentada de maneira ainda mais clara que s.v. ello.

Figura 10 - s.v. ello no DUE (2001)

ello. 1. Pron. Pers. Forma neutra de tercera persona. Se emplea cuando hace de sujeto y de complemento con preposición: 'Quería salir e inventó un pretexto para ello'. $\Rightarrow$ Apénd. II, PRONOMBRE PERSONAL. [...] 口 NOTAS DE USO: «Ello» hace referencia a una acción, estado, etc., y, por tanto, representa una oración como sujeto de otra $[\ldots]$.

Apéndice II, p. 1542: "La forma «ello» representa a una oración completa o un conjunto de antecedentes ya mencionados o consabidos: 'Todo ello no es inconveniente para que vengas'.

Fonte: DUE (2001, s.v. ello)

Finalmente, a unidade fraseológica ser más papista que el Papa é tratada no DRAEe (2014), no DiClave (2012) e no DUE (2001), mas não no DPDe (2005). Sobre as fraseologias, em particular, é importante ressaltar que, na teoria metalexicográfica, ainda não há orientações a respeito de como incluir fraseologias em um dicionário. A carência de orientação fica evidente no momento em que o consulente precisa buscar uma fraseologia, pois o processo de busca funciona por tentativa e erro. Mais especificamente, faz-se necessário buscar por cada constituinte da fraseologia até encontrá-la. O DRAEe (2014) e o DUE (2001) incluem a fraseologia s.v. papa ${ }^{1}$; o DiClave (2012), no entanto, a inclui s.v. papista.

No DRAEe (2014), no DUE (2001) e no DiClave (2012), a definição da fraseologia é apresentada de maneira simples e objetiva. Não restam dúvidas a respeito do seu significado, segundo se pode visualizar por meio das figuras 11, 12 e 13: 
Figura 11 - s.v. papa ${ }^{1}$ no DRAEe (2014)

papa $^{1}[\ldots]$ ser alguien más papista que el papa 1. loc. verb. Mostrar en un asunto más celo que el directamente interesado en ese asunto.

Fonte: DRAEe (2014, s.v. papa $\left.{ }^{I}\right)$

Figura 12 - s.v. papa ${ }^{1}$ no DUE (2001)

papa ${ }^{1}$. [...] SER alguien MÁS PAPISTA QUE EL PAPA. *Exagerar en la defensa de una cosa o en el celo o interés por ella, superando al o los directamente interesados. [...]

Fonte: DUE (2001, s.v. papa $\left.{ }^{l}\right)$

Figura 13 - s.v. papista no DiClave (2012)

papista pa·pis·ta ser más papista que el papa loc. verb. col. Ser extremadamente riguroso en el cumplimiento de un deber o de una recomendación.

Fonte: DiClave (2012, s.v. papista)

\section{Conclusões}

Em primeiro lugar, a lexicografia de aprendizes hispânica se encontra ainda em um estágio absolutamente insuficiente, porque não reflete completamente os fatos de norma da língua.

Em segundo lugar, o PCIC (2006) apresenta um elenco bastante detalhado dos insumos linguísticos necessários para aprimorar as diversas competências.

Em terceiro lugar, os dicionários monolíngues avaliados fornecem, de fato, uma ampla gama de informações que podem ajudar o estudante de Letras-espanhol a obter um desempenho satisfatório na língua.

Finalmente, é notória a necessidade de estudos que evidenciem de maneira mais sistemática a contribuição que os dicionários monolíngues podem dar para o ensino de ELE.

\section{Referências}

Actas del XII Congreso Brasileño de Profesores de Español (Cuiabá, 28 de agosto a 1 de septiembre de 2007). Brasilia: Embajada de España en Brasilia - Consejería de Educación, Ministerio de Educación de España, 2010. Disponível em: <http://www.mecd.gob.es/dmsstatic/5234cb65-282d-4086-a288-40f5398e596a/consejerias-exteriores/brasil/publicaciones-ymateriales--didacticos/publicaciones/otras/xiicongresoonline.pdf >. Acesso em: 14 dez. 2016.

BNCC. BRASIL. Ministério da Educação. Base Nacional Comum Curricular. $2^{\mathrm{a}}$ versão revista. Brasília: Secretaria da Educação Básica, 2016. Disponível em: 
$<$ http://basenacionalcomum.mec.gov.br/documentos/bncc-2versao.revista.pdf $>$. Acesso em: 18 ago. 2016.

BUGUEÑO MIRANDA, F. V. Léxico e Ensino: Señas (2000), um dicionário para aprendizes brasileiros de espanhol? In: MARTINS, E.; CANO, W.; MORAES FILHO, W. (org.). Léxico e morfofonologia: perspectivas e análises. Uberlândia: EDUFU, 2006, p. 213-227.

BUGUEÑO MIRANDA, F. V.; FARIAS, V. S. Desenho da macroestrutura de um dicionário escolar de língua portuguesa. In: XATARA, C; BEVILACQUA, C; HUMBLÉ, Ph. (orgs.). Lexicografia pedagógica: pesquisas e perspectivas. Florianópolis: UFSC/NUT, 2008, p. 129167.

BUGUEÑO MIRANDA, F. V.; REOLON JARDIM, C. Os learner's dictionaries do inglês e os Lernwörterbücher do alemão: uma simples transposição de nomes?. Contingentia, Porto Alegre, v. 5, p. 41-67, 2010. Disponível em: <http://seer.ufrgs.br/index.php/contingentia/article/view/13319/7614>. Acesso em: dez. 2016.

CNE/CES. BRASIL. Ministério da Educação. Conselho Nacional de Educação. Diretrizes Curriculares Nacionais dos cursos de Filosofia, História, Geografia, Serviço Social, Comunicação Social, Ciências Sociais, Letras, Biblioteconomia, Arquivologia e Museologia, 492/2001. Brasília, 2001. 38p. Disponível em: <http://portal.mec.gov.br/cne/arquivos/pdf/CES0492.pdf>. Acesso em: 05 mai. 2016.

CORPES. REAL ACADEMIA ESPAÑOLA. Corpus del Español del Siglo XXI. 2016. Disponível em: <http://www.rae.es/recursos/banco-de-datos/corpes-xxi>. Acesso em: 21 set. 2016.

CREA. REAL ACADEMIA ESPAÑOLA. Corpus de Referencia del Español Actual. 2010. Disponível em: <http://corpus.rae.es/creanet.html>. Acesso em: 21 set. 2016.

Ethnologue. Languages of the World. Disponível em: <http://www.ethnologue.com/statistics/size>. Acesso em: 07 ago. 2016.

ERES FERNÁNDEZ, G. et al. Materiais didáticos de espanhol: entre a quantidade e a diversidade. 2012. 68f. Relatório final de pesquisa não financiada - Faculdade de Educação, Universidade de São Paulo, São Paulo, 2012. Disponível em: <http://www4.fe.usp.br/cepel/pesquisa>. Acesso em: 18 ago. 2016.

JUDD, E. L.; TAN, L.; WALBERG, H. J. Teaching Additional Languages. Brussels: International Academy of Education; Geneva: International Bureau of Education, 2001. Disponível em: <http://www.ibe.unesco.org/fileadmin/user_upload/archive/Publications/educationalpracticess eriespdf/prac06e.pdf>. Acesso em: 18 ago. 2016.

PCIC. INSTITUTO CERVANTES. Plan Curricular del Instituto Cervantes. Niveles de referencia para el español. Madrid: Biblioteca Nueva, 2006. Disponível em: $<$ http://cvc.cervantes.es/Ensenanza/biblioteca_ele/plan_curricular/default.htm>. Acesso em: 19 ago. 2016.

INSTITUTO CERVANTES. Plan Curricular del Instituto Cervantes. Niveles A1 y A2. Madrid: Biblioteca Nueva, 2006a. 
INSTITUTO CERVANTES. Plan Curricular del Instituto Cervantes. Niveles B1

y B2. Madrid: Biblioteca Nueva, 2006 .

INSTITUTO CERVANTES. Plan Curricular del Instituto Cervantes. Niveles C1

y C2. Madrid: Biblioteca Nueva, 2006c.

PCN. BRASIL. Ministério da Educação. Parâmetros Curriculares Nacionais: terceiro e quarto ciclos do Ensino Fundamental. Língua Estrangeira. Brasília: Secretaria da Educação Fundamental, $1998 . \quad$ Disponível em: <http://portal.mec.gov.br/seb/arquivos/pdf/pcn_estrangeira.pdf>. Acesso em: 18 ago. 2016.

PCN. BRASIL. Ministério da Educação. Parâmetros Curriculares Nacionais para o Ensino Médio. Brasília: Secretaria da Educação Básica, 2000. Disponível em: <http://portal.mec.gov.br/seb/arquivos/pdf/14_24.pdf>. Acesso em: 18 ago. 2016.

PCN+. BRASIL. Ministério da Educação. PCN+ Ensino Médio: orientações educacionais complementares aos Parâmetros Curriculares Nacionais. Brasília: Secretaria da Educação Básica, 2002. Disponível em: 〈http://portal.mec.gov.br/seb/arquivos/pdf/linguagens02.pdf〉. Acesso em: 19 ago. 2016.

SCHLATTER, M.; GARCEZ, P. Educação linguística e aprendizagem de uma língua adicional na escola. In: RIO GRANDE DO SUL. Secretaria da Educação. Referenciais Curriculares do Rio Grande do Sul. Lições do Rio Grande. Porto Alegre, 2009. 257 p. Disponível em: <http://www.educacao.rs.gov.br/dados/refer_curric_vol1.pdf >. Acesso em: 05 mai. 2016.

SIEPMANN, D.; BÜRGEL, C. Das Corpus de réferénce du français contemporain (CRFC) und sein Einsatz in der Grammatikographie am Beispiel des Präpositionsgebrauch. In: SIEPMANN, Dirk; BÜRGEL, Christoph (Hrsgn.). Sprachwissenschaft und Fremdsprachendidaktik: Zum Verhältnis von sprachlichen Mitteln und Kompetenzentwicklung. Baltmannsweiler: Schneider Verlag Hohengehren, 2016, p. 141-159.

\section{Dicionários citados}

CCAD. HARPERCOLlinS. Collins Cobuid Advanced Dictionary. Boston: Heinle Cengage Learning, 2010.

DEB. UNIVERSIDAD ALCALÁ DE HENARES. Señas. Diccionario para la Enseñanza de la Lengua Española para Brasileños. São Paulo: Martins Fontes, 2008.

DEE. ESPASA CALPE. Diccionario de la Lengua Española para estudiantes de Español. Madrid: Espasa-Calpe, 2002.

DiClave. SM EDICIONES. Diccionario Clave de uso del español actual. Madrid: SM Ediciones, 2012. Disponível em: 〈http://clave.smdiccionarios.com/app.php〉. Acesso em: 16 set. 2016.

DPDe. REAL ACADEMIA ESPAÑOLA. Diccionario Panhispánico de Dudas. Madrid: Espasa-Calpe, 2005. Disponível em: <http://lema.rae.es/dpd/?key=a>. Acesso em: 26 set. 2016. 
DRAEe. REAL ACADEMIA ESPAÑOLA. Diccionario de la Lengua Española. Disponível em: <http://dle.rae.es/>. Acesso em: 16 set. 2016.

DSLEE. SANTILLANA. Diccionario Salamanca. Español para Extranjeros. Salamanca: Editorial Santillana / Universidad de Salamanca, 2006.

DUE. MOLINER, M. Diccionario de Uso del Español. Madrid: Gredos, 2001.

HARTMANN, R. R.; JAMES, G. Dictionary of Lexicography. London: Routledge, 2001.

LDCE. (2014). LONGMAN. Longman Dictionary of Contemporary English. London: Longman, 2014.

LGwtbDaF. Langenscheidt Großwörterbuch Deutsch als Fremdsprache. Berlin: Langenscheidt, 2015.

MDAL. MACMILLAN. Macmillan English Dictionary for Advanced Learners. Oxford: Macmillan, 2007.

OALD. OXFORD. Oxford Advanced Learner's Dictionary. Oxford: OUP, 2010.

RobCLE. Rey-Debove, J. (dir.). Le Robert \& CLE International Dictionnaire du français. Paris: Le Robert / CLE International, 1999. 